\title{
Parkinson Hastalarında D Vitamini Düzeyinin Osteoporotik Kırıklar ve Postür Bozukluğu ile ilişkilendirilmesi
}

\author{
Osteoporotic Fractures and Posture Problem in Association with Vitamin D Level in \\ Patients with Parkinson's Disease
}

\author{
Havva Talay Çalış, Serap Tomruk Sütbeyaz, Saliha Sunkak*, Mehtap Aykaç Çebicci, Canan Halıcı, \\ Asuman Çelikbilek**, Semra Yılmaz**, Fatma Gül Ülkü Demir \\ Kayseri Eğitim ve Araştırma Hastanesi, Fizik Tedavi ve Rehabilitasyon Kliniği, Kayseri, Türkiye \\ *Kayseri Eğitim ve Araştırma Hastanesi, Biyokimya Kliniği, Kayseri, Türkiye \\ **Kayseri Ĕ̈itim ve Araştırma Hastanesi, Nöroloji Kliniği, Kayseri, Türkiye
}

\section{$\ddot{O z}$}

\begin{abstract}
Amaç: Çalışmamıza Parkinson hastası olup vertebral fraktürü olan ve olmayan parkinsonlu hastalar alarak $D$ vitamin düzeylerinin osteoporotik vertebra fraktürleri ve postür bozukluğu ile ilişkisini açıklamayı amaçladık.

Gereç ve Yöntem: Çalışmamıza 40 yaş üzeri 59 Parkinson hastası alındı. D vitamini metabolizmasını bozabilecek hastalığı olanlar çalışmaya dahil edilmedi. yüksek basınçlı sıvı kromatografisi metodu ile plazmada 25-OH vitamin D düzeyleri, Ca, P, ALP, TSH, BUN, Cr değerleri ve DXA değerleri ölçüldü. Kemik mineral yoğunluğu ölçümü yapıldı. Lateral yönlü torakal ve lomber vertebra grafileri ile vertebral kırık varlığı lomber torakal olarak derecesi ve seviyesi belirtilerek yazıldı. Parkinson hastalığı evrelemesi Hohn Yahr Skalası'na göre yapıldı.

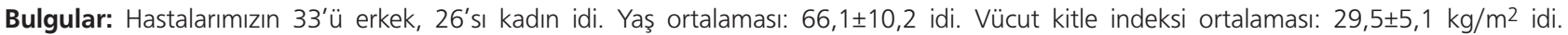
Hastalarımızın $35^{\prime}$ inin vertebral osteoporoz kırığı vardı ve 24 hastamızın vertebral osteoporoz kırığı yoktu. \%46,9 hastanın D vitamini seviyesi $10 \mathrm{IU} / \mathrm{dL}$ 'nin, \%83,7 hastanın ise $20 \mathrm{lU} / \mathrm{dL}$ 'nin altında idi. Bu normal popülasyonun çok altında idi. Vertebral kırığı olup, postür bozukluğu

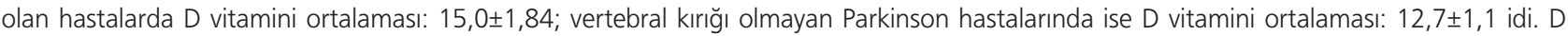
vitamini ile kırık varlığı arasında ise istatistiksel olarak anlamlıık saptanmadı $(p=0,005)$. Bizim çalışmamızda postür bozukluğu ile $D$ vitamini düzeyleri arasında istatistiksel olarak anlamlı bir ilişki bulunamamıştır. Ancak vitamin D düzeylerinin Parkinson hastalarında normal popülasyona göre düşük olduğu gösterilmiştir.
\end{abstract}

Sonuç: Vitamin D düzeylerinin Parkinson hastalarında düşük olabileceği akıldan çıkarılmamalıdır. Parkinson hastalarının kalça kııı̆ı, düşme ve yüksek osteoporoz riskini düşünerek D vitamini ve osteoporoz kontrolleri yapılmalıdır.

Anahtar kelimeler: Parkinson hastalığı, D vitamini, postür

\section{Abstract}

Objective: In our study, we aimed to clarify the relationship between vitamin D levels and osteoporotic vertebral fracture and posture problems in parkinson's disease patients with and without vertebral fracture.

Materials and Methods: In this study 59 Parkinson's disease patients (aged $\geq 40$ years) were included. Patients with a disease that may impair their vitamin D metabolism were not included to the study. 25-OH Vitamin D levels in plasma, Ca, P, ALP, PTH, TSH, BUN and Cr values and DXA values were measured from the obtained blood samples by high performance liquid chromatography method. Bone mineral density was measured. Lateral thoracic and lumbar vertebra radiographs were obtained, and vertebra fracture were recorded in as lumbar thoracic fracture with degree and level. Parkinson's disease staging was done using Hoehn Yahr Scale.

Results: There were 33 men and 26 women patients. In the study population, mean age was $66.1 \pm 10.2$ years while mean body mass index was $29.5 \pm 5.1 \mathrm{~kg} / \mathrm{m}^{2}$. Osteoporotic vertebral fracture was detected in 35 patients and it was not detected in 24 patients. Vitamin D level was less than $10 \mathrm{IU} / \mathrm{dL}$ in $46.9 \%$ of the patients and it was less than $20 \mathrm{IU} / \mathrm{dL}$ in $83.7 \%$ of them. This was lower than the normal population value. Mean vitamin D concentration was $15.0 \pm 1.84$ in Parkinson's disease patients with vertebral fracture and posture problems while it was $12.7 \pm 1.1$ in patients without vertebral fracture. There was no significant relation between vitamin $D$ and fracture presence $(p>0.005)$. In our study, no significant correlation was found between posture problem and vitamin D levels. However, it was shown that vitamin D levels were lower in Parkinson's disease patients than in general population.

Yazışma Adresi/Address for Correspondence: Dr. Havva Talay Çalış, Kayseri Eğitim ve Araştırma Hastanesi Fizik Tedavi ve Rehabilitasyon Kliniği, Kayseri, Türkiye Tel.: +90 5326874541 E-posta: htalaycalis@yahoo.com Geliş Tarihi/Received: 19.10.2016 Kabul Tarihi/Accepted: 07.04.2017 
Conclusion: It should be kept in mind that vitamin D levels might be low in patients with Parkinson's disease. Given the high risk for pelvic fracture, fall and osteoporosis, periodical vitamin D and osteoporosis examinations should be performed in Parkinson's disease patients.

Keywords: Parkinson's disease, vitamin D, posture

\section{Giriş}

Parkinson hastalığı, beyindeki hücre dejenerasyonu ile giden dopaminerjik nöronların harabiyetinden kaynaklanan progresif nörodejeneratif bir hastalıktır (1). Hücreler arası sinyalin iletilememesi sonucunda bazal ganglia'nın beyin korteksindeki uyarıcı etkisi azalmakta ve hareketlerin yavaşlaması, titreme, denge kayıpları gibi motor semptomlara yol açmaktadır (2). Parkinson hastalarında kalça ve diz fleksiyonuyla karakterize "öne eğik gövde" postürü de görülebilmektedir (3).

D vitamini kemik yapısı ve gelişimi açısından önemli bir vitamindir. D vitamini eksikliği kemik mineralizasyon yetersizliği, proksimal kas zayıflığı, postür (dorsal kifoz artışı) bozukluğuna neden olur. Düşme ve kırık riskini artırır (4). Buna ek olarak, Dopaminerjik nöronların da vitamin $D$ reseptörleri ile yakın ilişkisi olduğu gösterilmiştir. 1,25 $(\mathrm{OH}) 2 \mathrm{D}_{3}{ }^{\prime}$ ün dopaminerjik nöron gelişimini ve fonksiyonunu sağlayan nöron büyüme faktörü, glial kökenli nörotropik faktör gibi faktörleri de regüle eder. Bu nedenlerle Parkinson hastalığının etiyopatogenezinde D vitamini eksikliği rol oynayabilir (5).

Parkinsonlu hastalarda immobilizasyona sekonder ya da ikamet ettikleri coğrafi konuma bağlı olarak D vitamin eksikliği olabilir (6). Parkinson hastalığındaki öne eğik gövde postürü D vitamini eksikliği ile artabilir ve bu D vitamini takviyesi ile azaltılabilir (7). Biz de çalışmamızda vertebra fraktürü olan ve olmayan parkinsonlu hastalarda D vitamini düzeyi ile osteoporotik vertebra fraktürü, postür ve yürüyüş bozukluğu arasındaki ilişkiyi açıklamayı amaçladık.

\section{Gereç ve Yöntem}

Çalışmamıza Kayseri Eğitim ve Araştırma Hastanesi Fizik Tedavi ve Rehabilitasyon ve Nöroloji Polikliniği'ne başvuran 1992 Ingiltere Parkinson Hastalığı Derneği Beyin Bankası Klinik Tanı Kriterleri'ne göre Parkinson hastalığı tanısı almış 40 yaş üzeri 59 Parkinson hastası alındı. Primer hiperparatiroidi, renal, kardiyak ve tiroid fonksiyon bozukluğu olanlar, renal osteodistrofi, D vitamini metabolizmasını bozabilecek hastalığı olanlar, son 6 aydır kortikosteroid, östrojen, kalsitonin, bifosfonat, kalsiyum, D vitamini kullanmış hastalar çalışmaya alınmadı. Hastalar başvurularına göre ardı sıra alındı. Çalışma protokolü için Erciyes Üniversitesi Tıp Fakültesi Etik Kurulu'ndan onay alındı (2012/67) Helsinki Bildirgesi'ne göre hastalar çalışma ile ilgili bilgilendirilerek hasta onamları alındı.

Hastalara yaş, medeni durum, meslek, boy, kilo, menopoz yaşı, diyetle günlük kalsiyum alımı, günlük ve haftalık güneşlenme miktarı, kahve, alkol, sigara alışkanlığı, Parkinson hastalık süreleri sorgulandı.

Parkinson hastalığı Hohn Yahr Skalası'na (HYS) göre evrelenerek 5 evreye ayrıldı (8);
Evre 1: Tek taraflı tremor, rijidite, akinezi veya postüral dengesizlik.

Evre 2: iki taraflı tremor, rijidite, akinezi veya bradimimi, yutma güçlükleri, aksiyel rijidite (özellikle boyun) öne eğik gövde postürü, yavaş veya ayağını sürüyerek yürüme ve genel katılık gibi aksiyal bulgularla birlikte veya tek başına postüral anormallikler.

Evre 3: Evre 2'deki bulgulara ilaveten hastada denge bozuklukları vardır, ancak hastanın tüm aktivitelerini bağımsız olarak yapabilir.

Evre 4: Hasta günlük aktivitelerinin bir kısmında veya tamamında yardıma ihtiyaç duyar.

Evre 5: Hasta tekerlekli sandalye veya yatağa bağımlı durumdadır.

Hastaların hepsine postür değerlendirmesi (dorsal kifoz varlığı, lomber lordozda artış, skolyoz varlığı, flatback, kifolordoz, fleksiyon, lordozda düzleşme) yapıldı.

Mini-mental muayenede zaman-mekan oryantasyonu, kayıt, hesap, hatırlama, lisan testleri, şekil kopyalama testleri yapıldı (MMDT 19'un altı: kötü, 20-23 arası: orta, 24-30 arası: iyi olarak değerlendirildi) $(9,10)$.

Denge (statik ve dinamik) ve koordinasyon muayenesi parmak burun testi, diz topuk testi, tremor varlığı, disdiadokinezi, dissinerji, tek bacak üzerinde durma, romberg, tandem, kalk yürü testi ile yapıldı.

HPLC metodu ile Agilent 1200 cihazında Chroms Systems Kit kullanılarak EDTA'lı tüpten alınan 0,5 mL plazmada 25-OH vitamin D düzeyleri çalışıldı. Yine Hastaların kalsiyum, fosfor, alkalen fostofaz, paratiroid hormon, tiroid stimülan hormon, kan üre azotu, kreatinin değerleri ölçüldü. $25-\mathrm{OH}$ vitamin $D$ değeri $10 \mathrm{IU} / \mathrm{dL}$ 'nin altındakiler eksiklik, $20 \mathrm{IU} / \mathrm{dL}$ 'nin altındakiler yetmezlik olarak değerlendirildi (11).

Kemik mineral yoğunluğu ölçümü lomber vertebralardan (L1-L4 arası anterior pozisyonda) ve proksimal femurdan DXA cihazı (Lunar DPX-IQ) ile değerlendirildi.

Kırıklar radyografik olarak semikantitatif değerlendirme ile ölçüldü (12). Olguların lateral yönlü torakal ve lomber vertebra grafileri çekilerek tüm vertebralarda ön, orta, arka yükseklikler ölçüldü ve bir vertebranın üç yükseklik ölçümünden (ön, orta, arka) en az biri en yakın normal vertebranın yükseklik ölçümünden \%20 azalmış ise bu vertebral kırık olarak kabul edildi. Kırıklar lomber torakal olarak derecesi ve seviyesi belirtilerek yazıldı.

\section{İstatistiksel Analiz}

Veriler IBM SPSS version 22.0 istatistik paket programına girildi. Tüm değişkenlere öncelikle Shapiro Wilk testi uygulanarak değişkenlerin dağılımının normal dağılımlı olup olmadığı belirlendi. Normal dağılımlı değişkenler ortalama \pm standart sapma, normal dağılıma uymayan değişkenler 
ortalama (minimum-maksimum) olarak ifade edildi Normal dağılıma uymayan değişkenler açısından gruplar arası karşılaştırma yapılırken Mann-Whitney $U$ testi, normal dağılımlı değişkenlerde gruplar arası karşılaştırma yapılırken bağımsız iki örneklem t- testi kullanıldı. İkiden fazla grupların karşılaştırılmasında ki kare testi kullanıldı. Normal dağılıma uymayan verilerin ikili korelasyon analizinde Spearman korelasyon analizi kullanıldı. Anlamlılık değeri $p<0,05$ kabul edildi.

\section{Bulgular}

Hastaların demografik verileri ve vitamin D düzeyleri Tablo 1'de gösterilmiştir.

Çalışmaya alınan hastaların yaş ortalaması: $66,1 \pm 10,2$, vücut kitle indeksi: 29,5 $\pm 5,1$ idi. Parkinson hastalık süreleri ortalaması: 3 (1-10) yıl idi.

Hastaların 33'ü erkek, 26'sı kadın idi. D vitamini değerlerine bakıldığında kadın hastaların D vitamin ortalaması: 9,55 (7,913,02), erkek hastaların D vitamini ortalaması 14,3 $(9,2-17,8)$ idi. İstatistiksel olarak anlamlı derecede kadın hastaların $D$ vitamin düzeyi düşük olarak bulundu $(p=0,043)$.

Çalışmaya alınan hastaların \%83,7'sinde D vitamini seviyesi $20 \mathrm{IU} / \mathrm{dL}$ 'nin altında idi. Bunların \%46'sında ciddi D vitamini yetmezliği bulunup; D vitamini seviyesi $10 \mathrm{IU} / \mathrm{dL}$ altında idi. Gruplara göre (25-OH vitamin $D_{3} 10 \mathrm{IU} / \mathrm{dL}$ üzeri ve altı) parmak burun testi, diz topuk testi, tremor varlığı, disdiadokinezi, dissinerji, tek bacak üzerinde durma, romberg, tandem, kalk yürü testleri ile mini-mental muayenede istatistiksel olarak anlamlı fark saptanmadı ( $p>0,05)$.

Vertebra kırığı olup, postür bozukluğu olan hastalarda $D$

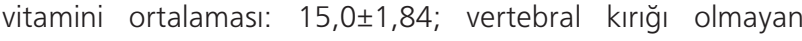
Parkinson hastalarında ise $D$ vitamini ortalaması: $12,7 \pm 1,1$ idi. $\mathrm{Bu}$ istatistiksel olarak anlamlı değildi $(p>0,05)$. Tablo 2'de D vitamini düzeyi ile kırık varlığı arasındaki ilişki gösterilmiştir. D

\section{Tablo 1. Hastaların demografik verileri ve vitamin D} düzeyleri

\begin{tabular}{|l|l|}
\hline Yaş $^{*}$ & 66,10 yıl $(43,00-87,00)$ \\
\hline Cinsiyet $(n=59)$ & $\begin{array}{l}\text { Kadın: } 26 \\
\text { Erkek: } 33\end{array}$ \\
\hline Vücut kitle indeksi* & $29,50\left(\mathrm{~kg} / \mathrm{m}^{2}\right)(21,90-46,90)$ \\
\hline Menopoz yaşı* & $45,76(30,00-50,00)$ yıl \\
\hline Parkinson hastalığı süresi* & $3(1-10)$ \\
\hline Vitamin D düzeyi* & $\begin{array}{l}\text { Kadın: } 9,55 \mathrm{IU} / \mathrm{dL}(7,9-13,0) \\
\text { Erkek: } 14,3 \mathrm{IU} / \mathrm{dL}(9,2-17,8)\end{array}$ \\
\hline \multicolumn{2}{|l|}{${ }^{*}$ Değerler [Ortalama (minimum-maksimum)] olarak ifade edildi. } \\
\hline
\end{tabular}

\section{Tablo 2. D vitamini düzeyine göre kırık varlığı *}

\begin{tabular}{|l|l|l|l|}
\hline D vitamin düzeyi & $\mathbf{n}$ & Kırık var $\mathbf{n}(\%)$ & Kırık yok n (\%) \\
\hline D vitamin $<10 \mathrm{IU} / \mathrm{dL}$ & 59 & $18(\% 62)$ & $11(\% 38)$ \\
\hline D vitamin $>10 \mathrm{IU} / \mathrm{dL}$ & 59 & $17(\% 57)$ & $13(\% 43)$ \\
\hline${ }^{*}$ Ki-kare analizi, $\mathrm{p}>0,05$ &
\end{tabular}

vitamini düzeyi ile kırık varlığı arasında ise istatistiksel olarak anlamlı ilişki saptanmadı ( $p=0,673)$.

Hastaların $35^{\prime}$ inde $(\% 59,32)$ osteoporotik vertebra kırı̆ı tespit edildi. Hastaların 15'inde tek vertebra kırığı, 20'sinde çoklu vertebra kırığı bulunmaktaydı. Tablo 3'de D vitamini düzeyi ile kırık sayısı arasındaki ilişki gösterilmiştir. Vertebra kırıklarının 16 'sı torakal, 7'si lomber, 12'si torakal+lomber bölgede idi.

Hastaların \%40,7'sinin HYS'si 1 idi. Kırk dokuz hastanın HYS'si 1 veya 2 idi. Yine 54 hastanın HYS'si 1,2,3 idi. HYS ile D vitamin düzeyleri arasında istatistiksel olarak anlamlı bir fark bulunmadı $(p=0,536)$ (Tablo 4).

\section{Tartışma}

Parkinson hastalığında ileri yaş, immobilite, anormal postür, malnütrisyon gibi bir çok risk faktörü $D$ vitamini eksikliğine neden olabilir. Evatt ve ark.'nın (4) Atlanta'da yaptığı çalışmada 100 parkinson ve 97 Alzhemier hastasını sağlıklı kontrollerle karşılaştırmışlar ve Parkinson hastalarında 25-OH vitamin $D_{3}$ düzeylerinin ortalama $31,9 \pm 13,6 \mathrm{IU} / \mathrm{dL}$ olarak göstermişlerdir. Parkinson hastalarının \%55'inde D vitamin düşüklüğü saptamışlardır. Parkinson hastalığındaki D vitamin eksikliği prevelansı Alzheimer hastalığı olanlardan ve sağlıklı kontrollerden önemli derecede daha yüksek bulmuşlardır. Bu durum Parkinson hastalığının Alzheimer hastalığından daha uzun seyretmesine ve hareket bozukluklarının daha fazla immobiliteye yol açmasına bağlanmıştır. Bizim çalışmamızda da hastaların \%83,7'sinin D vitamin düzeyi $20 \mathrm{lU} / \mathrm{dL}$ 'nin altında olup ve Evatt ve ark.'nın (4) çalışması ile uyumlu olarak normal düzeye göre düşük bulunmuştur.

Ülkemizde ve dünyada D vitamini eksikliği/yetersizliği yaygın olarak görülmektedir (13). D vitamin eksikliği aslında tüm dünyada önemli sağlık problemlerine yol açmaktadır (14). Ülkemizde Uçar ve ark.'nın (15) bizim bölgemizle aynı bölgede yaptığı çalışmada oldukça yüksek oranda $(\% 51,8)$ D vitamini eksikliği ve \%20,7 oranında D vitamini yetersizliği tespit etmişlerdir. Ancak bizim çalışmamızdaki D vitamini eksikliği oranı bu oranın çok üzerindedir. Bu da coğrafi faktörlerden

Tablo 3. D vitamini düzeyi ile kırık sayısı arasındaki
ilişki*
\begin{tabular}{|l|l|l|l|}
\hline Vitamin D düzeyi & $\begin{array}{l}\text { Kırık yok } \\
\text { n (\%) }\end{array}$ & $\begin{array}{l}\text { 1 adet } \\
\text { kırık n (\%) }\end{array}$ & $\begin{array}{l}\text { Multipl kırık } \\
\text { sayısı n (\%) }\end{array}$ \\
\hline D vit $\leq 10 \mathrm{IU} / \mathrm{dL}$ & $11(\% 38)$ & $6(\% 20)$ & $12(\% 42)$ \\
\hline D vit $>10 \mathrm{IU} / \mathrm{dL}$ & $13(\% 43)$ & $9(\% 30)$ & $8(\% 27)$ \\
\hline *Ki-kare analizi, p>0,05 & & & \\
\hline
\end{tabular}

Tablo 4. HYS ile D vitamin düzeyleri arasındaki ilişki *

\begin{tabular}{|l|l|l|}
\hline \multirow{2}{*}{ Vitamin D düzeyi } & \multicolumn{2}{|c|}{ HYS } \\
\cline { 2 - 3 } & Evre 1 ve 2 & Evre 3, 4 ve 5 \\
\hline D vitamin $\leq 10 \mathrm{IU} / \mathrm{dL}$ & $23(\% 79,3)$ & $6(\% 20,7)$ \\
\hline D vitamin $>10 \mathrm{IU} / \mathrm{dL}$ & $26(\% 86,7)$ & $4(\% 13,3)$ \\
\hline${ }^{*}$ Fisher kesin testi, $\mathrm{p}>0,05, \mathrm{HYS}:$ Hohn Yahr Skalası \\
\hline
\end{tabular}


bağımsız olarak Parkinson hastalığııın kendisinin de D vitamini eksikliğine yol açabilmesiyle açılkanabilir.

Mogadashi ve ark.'nın (16) 83 parkinsonlu hastada D vitamin düzeyini incelemişler. Çalışmalarında diğer çalışmalara göre $25-\mathrm{OH}$ vitamin $\mathrm{D}_{3}$ düzeyinin daha düşük olduğunu ve özellikle postüral stabilite ve katılık ile düşük $\mathrm{D}$ vitamin düzeyleri arasında ileri düzeyde anlamlı ilişki olduğunu tespit etmişlerdir. Bunu da coğrafik konuma, hastaların giyim şekline, diyetle aldıkları D vitamin düzeyine ve güneş ışığına doğrudan maruz kalma süresine bağlamışlardır. Kadın erkek hastaların D vitamin düzeyleri arasında ise anlamlı farklılık gösterememişlerdir. Bizim çalışmamızda ise kadın hastaların $D$ vitamini düzeyi erkek hastalarınkine göre istatistiksel olarak anlamlı derecede düşüktü. Bu da bizim toplumumuzun giyim tarzından ve kadın hastalarımızın fiziksel olarak daha inaktif olmasından ve daha az güneşe çıkmasından kaynaklanabilir.

D vitamininin beyinde önemli etkilere sahip olabileceği ve santral sinir sisteminde hücre proliferasyonunda, diferansiyasyonda, nörotransmisyonda, nöroplastisitede farklı değişken rollere sahip olduğu ve nörotrofik, nöroprotektif etki gösterdiği belirtilmiştir. Parkinson hastalarında hareket bozukluğunun yanı sıra hastalığın ilerleyen dönemlerinde depresyon ve kognitif fonksiyon bozukluğu ortaya çıkabilir. Biz de çalışmamızda hastaların kognitif fonksiyonları değerlendirmek için mini mental durum testi (MMDT) kullandık. Hastaların vitamin $D$ düzeyi ve MMDT arasında anlamlı ilişki saptamadık $(p=0,646)$. Safer ve ark.'nın (17) yapmış olduğu çalışmada 45 postmenopozal osteoporozu olan kadın hastaya 1 yll boyunca verilen D vitamini supplementasyonu ile MMDT'de bizim çalışmamıza benzer şekilde anlamlı bir değişiklik olmadığı gösterilmştir. Ahn ve Kang (18) 108 erkek ve 304 kadın Koreli yaşlı hastanın incelendiği çalışmalarında Vitamin D düzeyi ile Mini-Mental Durum Testi arasında pozitif korelasyon bulmuşlardır. Bizim çalısmamızdaki hasta sayısının Ahn ve Kang'ın (18) yaptığı çalışmadaki hasta sayısından çok az olması da bunda etkili olmuş olabilir.

Evatt ve ark.'nın (4) ayrıca Hohn Yahr evrelemesi ve hastalı̆ıın süresi ile D vitamini eksikliğinin anlamlı derecede ilişkili olduğunu göstermişlerdir. Bizim hastalarımızın çoğunda Hohn Yahr evrelemesi evre 1, 2 idi. Yani günlük yaşam aktivitelerini bağımsız olarak yapabiliyorlardı. Bu da immobilizasyon dışında Parkinson hastalı̆̆ının kendisinin de $\mathrm{D}$ vitamini düzeylerini etkileyebileceğini göstermektedir.

Vitamin D eksikliği özellikle postüral denge ve yürüyüş için gerekli olan alt ekstremitenin yük taşıyan antigravite kaslarını etkilemektedir. Vitamin D eksikliği olan yaşı popülasyonda vitamin $D$ takviyesinin kas gücünü, yürüme mesafesini ve fonksiyonel yetenekleri artırdığı, düşmeleri ve nonvertebral kırıkları azalttığı gösterilmiştir (19). Mowe ve ark.'nın (20) yapmış olduğu çalışmada 246 hastaneye yatan 103 ayaktan hastanın değerlendirildiği çalışmada kas fonksiyondaki azalma ile düşük vitamin $D$ düzeyi arasında anlamlı ilişki bulunmuştur. Çalışmamızda alt ekstremite fonksiyonunu, denge (statik ve dinamik) ve koordinasyonu değerlendirmek için parmak burun testi, diz topuk testi, tremor varlığı, disdiadokinezi, dissinerji, tek bacak üzerinde durma, romberg, tandem, kalk-yürü testini kullandık. Vitamin D düzeyi ve bu testler arasında anlamlı ilişki saptamadık. Bizim çalışmamızdaki hasta sayımız Mowe ve ark.'nın (20) yapmış olduğu çalışmadan daha az olması bunun nedeni olabilir. Bunun dışında bizim olgularımızın demografik verilere ve eşlik eden hastalıklara göre analiz yapılmamış olmasıyla ilişkilendirilebilir.

Sato ve ark.'nın (21) yaptığı çalışmada ise D vitamini takviyelerinin yaşı kişilerde düşmelerin riskini azaltabileceği söylenmektedir. Sato ve ark.'nın (22) Parkinson hastalığı olan kadınlarda görülen nonvertebral kırık insidansının daha yüksek olduğunu ve bunun da osteoporoz kaynaklı D vitamini eksikliğine bağı düşme sıklığının artışına bağlamışlardır.

Bizim çalışmamızda postür bozukluğu ile $D$ vitamini düzeyleri arasında istatistiksel olarak anlamlı bir ilişki bulunamamışıı. Ancak vitamin $D$ düzeylerinin Parkinson hastalarında normal popülasyona göre düşük olduğu gösterilmiştir.

\section{Sonuç}

Vitamin D düzeylerinin Parkinson hastalarında düşük olabileceği akıldan çıkarılmamalıdır. Parkinson hastalarının kalça kıı̆ğı, düşme ve yüksek osteoporoz riskini düşünerek $D$ vitamini ve osteoporoz kontrolleri yapılmalıdır.

\section{Etik}

Etik Kurul Onayı: Erciyes Üniversitesi Tıp Fakültesi Etik Kurulu'ndan onay alındı (Onay no: 2012/67), Hasta Onayı: Helsinki bildirgesine göre hastalar çalışma ile ilgili bilgilendirilerek hasta onamları alındı.

Hakem Değerlendirmesi: Editörler kurulu tarafından değerlendirilmiştir.

\section{Yazarlık Katkıları}

Konsept: H.T.Ç., S.T.S., Dizayn: H.T.Ç., S.T.S., S.S., M.A.Ç., Veri Toplama veya isşleme: H.T.Ç., S.S., A.Ç., S.Y., C.H., Analiz veya Yorumlama: H.T.Ç., S.T.S., M.A.Ç., F.G.Ü.D., Literatür Arama: H.T.Ç., S.T.S., S.S., Yazan: H.T.Ç., S.T.S., S.S., F.G.Ü.D.

Çıkar Çatışması: Yazarlar arasında herhangi bir çıkar çatışması yoktur.

Finansal Destek: Kayseri Eğitim ve Araştırma Hastanesi kurumundan alınmıştır.

\section{Kaynaklar}

1. Newmark HL, Newmark J. Vitamin D and Parkinson's disease: $A$ hypotesis. Mov Disord 2007;22:461-8.

2. Hilker R, Schweitzer K, Coburger S, Ghaemi M, Weisenbach S, Jacobs $\mathrm{AH}$, et al. Nonlinear progression of Parkinson disease as determined by serial positron emission tomographic imaging of striatal fluorodopa F18 activity. Arch Neurol 2005;62:37882.

3. Pandey S, Garg H. Postural \& striatal deformities in Parkinson `s disease: Are these rare? Indian J Med Res 2016;143:11-7.

4. Evatt ML, Delong MR, Khazai N, Rosen A, Triche S, Tangpricha $V$. Prevalence of vitamin $d$ insufficiency in patients with Parkinson disease and Alzheimer disease. Arch Neurol 2008;65:1348-52

5. Eyles DW, Smith S, Kinobe R, Hewison M, McGrath JJ. Distribution of the vitamin $D$ receptor and 1 alpha-hydroxylase in human brain. J Chem Neuroanat 2005;29:21-30. 
6. Ginde AA, Liu MC, Camargo CA Jr. Demographic differences and trends of vitamin D insufficiency in the US population, 1988-2004. Arch Intern Med 2009;169:626-32.

7. Sato $Y$, Kikuyama M, Oizumi K. High prevalence of vitamin $\mathrm{D}$ deficiency and reduced bone mass in Parkinson's disease. Neurology 1997:49:1273-8.

8. Goetz CG, Poewe W, Rascol O, Sampaio C, Stebbins GT, Counsell C, et al; Movement Disorder Society Task Force on Rating Scales for Parkinson's Disease. Movement Disorder Society Task Force report on the Hoehn and Yahr staging scale: status and recommendations. Mov Disord 2004;19:1020-8.

9. Folstein MF, Folstein SE, McHugh PR. "Mini-Mental State": a practical method for grading the cognitive state of patients for the clinician. J Psychiatr Res 1975;12:189-98.

10. Güngen C, Ertan T, Eker E, Yaşar R, Engin F. Standardize Mini Mental Test'in Türk toplumunda hafif demans tanısında geçerlilik ve güvenilirliği. Türk Psikiyatri Dergisi 2002;13:273-81.

11. Binkley N, Ramamurthy R, Krueger D. Low vitamin D status: definition, prevalence, consequences, and correction. Endocrinol Metab Clin North Am 2010;39:287-301.

12. Genant HK, Wu CY, van Kuijk C, Nevitt M. Vertebral fracture Assessment using a semi-quantitative technique. J Bone Miner Res 1993;8:1137-48.

13. Fidan $F$, Alkan B $M$, Tosun A. Türkiye Çağın Pandemisi D Vitamini Eksikliği ve Yetersizliği Türk Osteoporoz Dergisi 2014;20:71-4.
14. Wacker M, Holick MF. Vitamin D-Effects on Skeletal and Extraskeletal Health and the Need for Supplementation. Nutrients 2013;5:111-48

15. Uçar F, Taşlıpınar MY, Soydas AÖ, Özcan N. Ankara Etlik intisas Eğitim Araştırma Hastanesi'ne Başvuran Hastalarda 25-OH Vitamin D Düzeyleri. Eur J Basic Med Sci 2012;2:12-5.

16. Mogadashi M, Mamarabadi M, Aghaii M. Serum 25-hydroxyvitamin D3 concentration in Iranian patients with Parkinson's disease. Iran J Neurol 2013;12:56-9.

17. Safer U, Safer VB, Demir SO, Yanikoglu I. Effects of Bisphosphonates and Calcium plus Vitamin-D Supplements on Cognitive Function in Postmenopausal Osteoporosis§. Endocr Metab Immune Disord Drug Targets 2016;16:56-60.

18. Ahn JD, Kang H. Physical Fitness and Serum Vitamin D and Cognition in Elderly Koreans. J Sports Sci Med 2015;14:740-6.

19. Janssen HC, Samson MM, Verhaar HJ. Vitamin D deficiency, muscle function, and falls in elderly people. Am J Clin Nutr 2002;75:611-5.

20. Mowe M, Haug E, Bohmer T. Low serum calcidiol concentration in older adults with reduced muscular function. J Am Geriatr Soc 1999:47:220-6

21. Sato $Y$, Iwamoto J, Honda Y. Amelioration of osteoporosis and hypovitaminosis D by sunlight exposure in Parkinson's disease. Parkinsonism Relat Disord 2011;17:1-23.

22. Sato Y, Honda Y, Iwamoto J, Kanoko T, Satoh K. Abnormal bone and calcium metabolism in immobilized Parkinson's disease patients. Mov Disord 2005:20:1598-603. 